Integrated Environmental Assessment and Management — Volume 6, Number 3 - pp. 502-503

(c) 2010 SETAC

\title{
INCORPORATING ENVIRONMENTAL VARIABILITY FROM RAPID CLIMATE CHANGE INTO ECOTOXICOLOGY TESTS
}

\author{
John Cairns Jr. \\ Virginia Polytechnic Institute and State University, \\ Blacksburg, Virginia, USA \\ jcairns@vt.edu \\ DOI: 10.1002/ieam.80
}

As most complex, multivariate systems (such as climate) approach disequilibrium, variability of critical attributes increases markedly. Ecotoxicological tests, both laboratory and field, should incorporate relevant aspects of this variability into their testing procedures. A major problem with all variability studies is replication. Variation in a few randomly selected variables may not always be in concert with the majority of variables, as is usually the case in natural systems replication. As always, the researcher is faced with balancing environmental realism with replicability. This situation will worsen as environmental variability increases. One factor, selecting appropriate test species from a highly variable environment, will be problematic. In a highly variable environment, native species poorly adapted to a different environment will probably decline or even die off in the new environment. Because environmental change varies from one area to another, specimens of species indigenous to the damaged habitat might be available in another area. However, the only justification for using them as test species would be that the now highly variable environment would return to its previous condition in the near future. Otherwise, selecting from the invasive species is probably the best option. This approach means learning how to use the invasive species in toxicity tests so that the controls do not have unacceptable

levels of death and so that the results make sense for the ecosystem in question.

Unless major reductions in anthropogenic greenhouse gas emissions are immediate, the invasive species will become the new indigenous species, and the toxicity tests can be used in the usual way. However, if greenhouse gas emissions continue to rise, the testing process will have to be modified again. In short, if a high degree of variability continues, flexibility in developing new procedures will be a continuing necessity. In fact, if a major climatic tipping point is passed, the changes will be irreversible (Solomon et al. 2009) and the transition to a new, dynamic variability will be the "norm" until evolutionary processes replace the species driven to extinction with a new but different array of species. Assuming that Homo sapiens survives the catastrophe, the same procedures will probably suffice, although the species and environmental conditions will almost certainly be markedly different. Other variables will also be difficult to estimate, such as what toxics will be ubiquitous in ecosystems, what type of industries will be common, what types of waste treatments will be used, and what energy sources will dominate. In many areas of the world, freshwater for dilution of wastes has lessened; for example, Xu et al. (2009) note that business-as-usual emissions of greenhouse gases and black soot will result in the loss of most Himalayan glaciers in this century. In addition, rainfall patterns are changing, which is just one factor in the new ecotoxicology. Perhaps an array of application factors could be developed for different degrees of variability: a measure of ecosystem resilience that could be determined with various ecosystem assessments. Possibly the most important aspect of variability is that human climate forcing is four orders of magnitude (10 000 times) more powerful than natural forcing (Hansen 2009, p 161). Other indications show that the variability and rate of change will be unprecedented. Creative test procedures will be essential under these circumstances.

\section{REFERENCES}

Hansen J. 2009. Storms of my grandchildren: The truth about the coming climate catastrophe and our last chance to save humanity. New York (NY): Bloomsbury USA.

Solomon S, Plattner G-K, Knutti R, Friedlingstein P. 2009. Irreversible climate change due to carbon dioxide emissions. Proc Natl Acad Sci USA 106:1704-1709.

Xu BJ, Xu B, Cao J, Hansen J, Yao T, Joswia DR, Wang N, Wu G, Wang M, Zhao H, Yang W, Liu X, He H. 2009. Black soot and the survival of Tibetan glaciers. Proc Natl Acad Sci USA. DOI:10.1073/pnas.0910444106. 